\title{
Evaluation of the Aichi Biodiversity Targets: The international collaboration trilemma in interdisciplinary research
}

\author{
Minh-Hoang Nguyen 1,2,* \\ Quan-Hoang Vuong ${ }^{2}$
}

\author{
${ }^{1}$ Graduate School of Asia Pacific Studies, Ritsumeikan Asia Pacific University, Beppu, \\ Oita 874-8577, Japan \\ ${ }^{2}$ Centre for Interdisciplinary Social Research, Phenikaa University, Yen Nghia Ward, \\ Ha Dong District, Hanoi 100803, Vietnam
}

(*) Corresponding author; email: ng19m6tk@ apu.ac.jp

\begin{abstract}
Given the pros and cons of tourism on biodiversity, at least 12 of the 20 Aichi Biodiversity Targets are directly or indirectly related to tourism. Meanwhile, Target 19 aims to raise the generation, transfer, and application of knowledge on the topic of biodiversity. The objective of this study is, therefore, to evaluate the impact of Aichi Biodiversity Targets on the interdisciplinary research output, quality, and collaboration at the national scale regarding biodiversity and tourism. The Hamiltonian MCMC technique, incorporating the bibliometric analysis, was performed on 1,003 documents extracted from the Web of Science database. The current investigation revealed two prominent findings. First, the Aichi Biodiversity Targets induced positive effects on scientific productivity, quality, and international collaboration at the national level. Still, more than half of the countries on Earth (55.02\%) had not acquired any interdisciplinary publication on the topic of biodiversity and tourism.

Moreover, international collaboration was found to be an effective measure to improve scientific quality and quantity in both periods before and after the Aichi Targets. Nevertheless, whereas the effect of international collaboration on scientific output was similar between the two periods, its impact on scientific quality during 2011-2020 was lower than during 1991-2010. Thus, we argue that international cooperation cannot be used as a "silver bullet" strategy for advancing knowledge in the interdisciplinary field between biodiversity and tourism due to the trilemma between quantity, quality, and cost. Eventually, we recommend policymakers, funding evaluators, and researchers to put culture into perspective for lessening the cost of interdisciplinary research.
\end{abstract}

Keywords: biodiversity conservation; tourism; protected areas; international collaboration; mindsponge; Bayesian analysis 


\title{
1. Introduction
}

\author{
"The health of ecosystems on which we and all \\ other species depend is deteriorating more rapidly \\ than ever. We are eroding the very foundations of \\ our economies, livelihoods, food security, health \\ and quality of life worldwide."
}

- Robert Watson, Chair of the IPBES -

The world is now facing an unprecedented shrinking rate of biodiversity across all ecosystems. The Intergovernmental Science-Policy Platform on Biodiversity and Ecosystem Services (2019) reported that around 1 million species are threatened with extinction due to the increasing production and exploitation demand of more than 7.8 billion people. Just recently, Leihy et al. (2020) reveal that biodiversity features are rarely observed in $99.6 \%$ of Antarctica's wilderness area. For tackling the escalating biodiversity loss rate, there have been substantial resources and efforts being spent on conserving global biodiversity since the initiation of the Convention on Biological Diversity (CBD) in 1992. Besides Goal 15 set out in the 2030 Agendas for Sustainable Development by the United Nations, the 2010 Biodiversity Target and Aichi Biodiversity Targets are also initiated for reducing the biodiversity loss at the global scale. Among 20 targets of Aichi Biodiversity Target, Target 19 focuses specifically on transferring, sharing, and applying knowledge related to biodiversity.

Protected areas - including national parks, wilderness areas, community-conserved areas, and nature reserves - are useful tools for biodiversity conservation (Bruner, Gullison, 
Rice, \& Da Fonseca, 2001; IUCN, 2020; Myers, Mittermeier, Mittermeier, Da Fonseca, \& Kent, 2000; Sheehan, Stevens, Gall, Cousens, \& Attrill, 2013; Taylor et al., 2011). Since the first formal protected area in 1864, the number of protected landscapes and seascapes has grown dramatically to accomplish more and more complex objectives (Watson, Dudley, Segan, \& Hockings, 2014). Beginning with the mission to protect spectacular natural features and wildlife (Phillips, 2004), protected areas, especially in developing countries, are more recently expected to be not only the solution for local socioeconomic development (Ferraro \& Hanauer, 2011; Naughton-Treves, Holland, \& Brandon, 2005) but also the supplier of ecosystem services (Lubchenco, Palumbi, Gaines, \& Andelman, 2003; Postel \& Thompson Jr, 2005; Soares-Filho et al., 2010). However, keeping the operation of protected areas management and biodiversity conservation activities is a financial burden for governments and organizations (Dharmaratne, Sang, \& Walling, 2000; Emerton, Bishop, \& Thomas, 2006; Thur, 2010).

Beyond the financial subsidies from governments and international organizations, nature-based tourism expenditure is another primary income source of protected areas, especially those in emerging countries where governments have limited financial capacity. Balmford et al. (2015) estimate that nature-based tourism visits can generate approximately $\$ 600$ billion per annum in direct in-country expenditure and $\$ 250$ billion per annum in consumer surplus. If the influx of tourism income is capitalized efficiently, the finance of protected areas will be more sustainable, while conservation and local livelihood can be improved (Baral, Stern, \& Bhattarai, 2008; Ferraro \& Hanauer, 2011; Naughton-Treves et al., 2005; Thur, 2010; Walpole \& Goodwin, 2001). Despite the economic benefits, tourism is among the reasons that directly and indirectly contribute to the unsuccessful 
accomplishment of the 2010 Biodiversity targets (Hall, 2010b). It is the driver of five major causes of biodiversity loss, namely: overexploitation, habitat change, pollution, invasive species, and climate change (Gössling, 2002; Gössling \& Hall, 2006; Hall, 2010a).

To tackle the negative impact and maximize the benefits of tourism on biodiversity conservation, tourism is considered a fundamental factor in achieving the Aichi Biodiversity Target. At least 12 out of 20 Aichi Biodiversity Targets need the direct or indirect contribution of tourism for being achieved (Secretariat of the Convention on Biological Diversity 2015). Given the mutual impact of biodiversity and tourism, research on their relationship is crucial for effective protected area stewardship and policymaking. Evidencebased strategies also result in cost-effective, practical measures, such as restoration, protection, reintroduction, etc. (CBD High-Level Panel, 2014).

Current biodiversity issues require integration of natural and social sciences to be solved, so interdisciplinary research projects are essential to inform better results for policymaking and advance scientific understanding (Pongsiri \& Roman, 2007; Sievanen, Campbell, \& Leslie, 2012; Visseren-Hamakers, Gupta, Herold, Peña-Claros, \& Vijge, 2012). Even though the research productivity and collaboration regarding biodiversity have been studied using bibliometric methods (Dangles et al., 2016; Tydecks, Jeschke, Wolf, Singer, \& Tockner, 2018), little is known about those of interdisciplinary research about biodiversity.

In addition to that, to effectively prepare for the post-2020 global biodiversity framework, the CBD invites contribution to achieve the 2050 Vision for Biodiversity under the Decision 14/34 (Convention on Biological Diversity, 2018b). In response to the invitation, the current paper aimed to evaluate the impact of Aichi Biodiversity Targets on 
interdisciplinary studies regarding the mutual relationship between biodiversity and tourism in protected areas. As making scientific knowledge enhanced and transferred is emphasized in Target 19, we attempted to evaluate the knowledge advances through knowledge output, quality, and the effect of international collaboration on scientific production and quality. The evaluation, therefore, addressed the following research questions (RQ):

RQ1: Does global scientific productivity regarding tourism and biodiversity increase after the implementation of Aichi Biodiversity Targets?

RQ2: Does global scientific quality regarding tourism and biodiversity increase after the implementation of Aichi Biodiversity Targets?

RQ3: Does global international collaboration regarding tourism and biodiversity increase after the implementation of Aichi Biodiversity Targets?

RQ4: How does global international collaboration affect scientific productivity regarding tourism and biodiversity after implementing Aichi Biodiversity Targets?

RQ5: How does global international collaboration affect scientific quality regarding tourism and biodiversity after the implementation of Aichi Biodiversity Targets?

\section{Methodology}

\subsection{Materials}

The data employed in the current study were extracted from the Web of Science (WoS) database. Together with Scopus, the WoS database is among the world's most trusted databases 
for qualified documents and journals across disciplines. Due to its credibility and comprehensive platform, records provided by the WoS database have been widely used for policymaking and performance assessment by various academic, corporate, and government institutes.

Since we attempted to evaluate the scientific productivity, quality, and collaboration of the interdisciplinary topic between tourism and biodiversity, only documents simultaneously related to tourism, biodiversity, and protected area were comprised in the analysis. In other words, the current study's targets were documents belonging to the intersection area of research fields regarding biodiversity, tourism, and protected areas. We limited only studies in protected areas because of two reasons: 1) the primary functions of PAs are biodiversity and ecosystem conservation and sustainment of social and community objectives (Watson et al., 2014); and 2) the role of PAs is emphasized in Strategic Goal C of the Aichi Biodiversity Targets for safeguarding ecosystems, species, and genetic diversity (Convention on Biological Diversity, 2018a).

The search queries consisted of three major sets of keywords corresponding to biodiversity, tourism, and protected areas, respectively.

- Set 1 (Biodiversity): TS = (biodiversity OR "biological diversity" OR "wildlife diversity" OR "animal diversity" OR "plant diversity" OR "fauna* diversity" OR "flora* diversity" OR "species diversity" OR "ecosystem diversity" OR "habitat diversity" OR "genetic diversity")

- Set 2 (Tourism): TS = ("tour*" OR "visitor*")

- Set 3 (Protected area): TS = ("protected area*" OR "conservation area*" OR "wilderness area*" OR "conserved area*" OR "reserved area*" OR "nature reserve*" OR 


\begin{abstract}
"national park*" OR "natural monument*" OR "habitat management area*" OR "species management area*" OR "protected landscape*" OR "protected seascape*")
\end{abstract}

We defined biodiversity as "the variability among living organisms from all sources including, inter alia, terrestrial, marine and other aquatic ecosystems and the ecological complexes of which they are part; this includes diversity within species, between species and of ecosystems" following the definition of CBD (Convention on Biological Diversity, 2006). As such, the first set of keywords included all the terms that are the synonym or components of biological diversity. Meanwhile, the second set of keywords tried to cover all documents mentioning "tour*" (tour, tourist, or tourism, etc.) or "visitor" (visitor or visitors), which are representatives of tourism. Lastly, given the wide variety of protected areas, we adopt the keywords from IUCN's category of protected areas (Dudley, Shadie, \& Stolton, 2013).

We had not applied any inclusion criteria on the entire sets of keywords before the search during the searching process. Next, we combined the search results of these three sets of keywords using a Boolean AND. Eventually, 1,150 publications that were concurrently related to tourism, biodiversity, and protected area were extracted.

\title{
2.2. Quality control
}

For controlling the accuracy and robustness of analyzed data, we followed the PRISMA (Preferred Reporting Items for Systematic Reviews and Meta-Analyses) guidelines for selecting eligible publications. Figure 1 presents the PRISMA process adopted by the current study. 


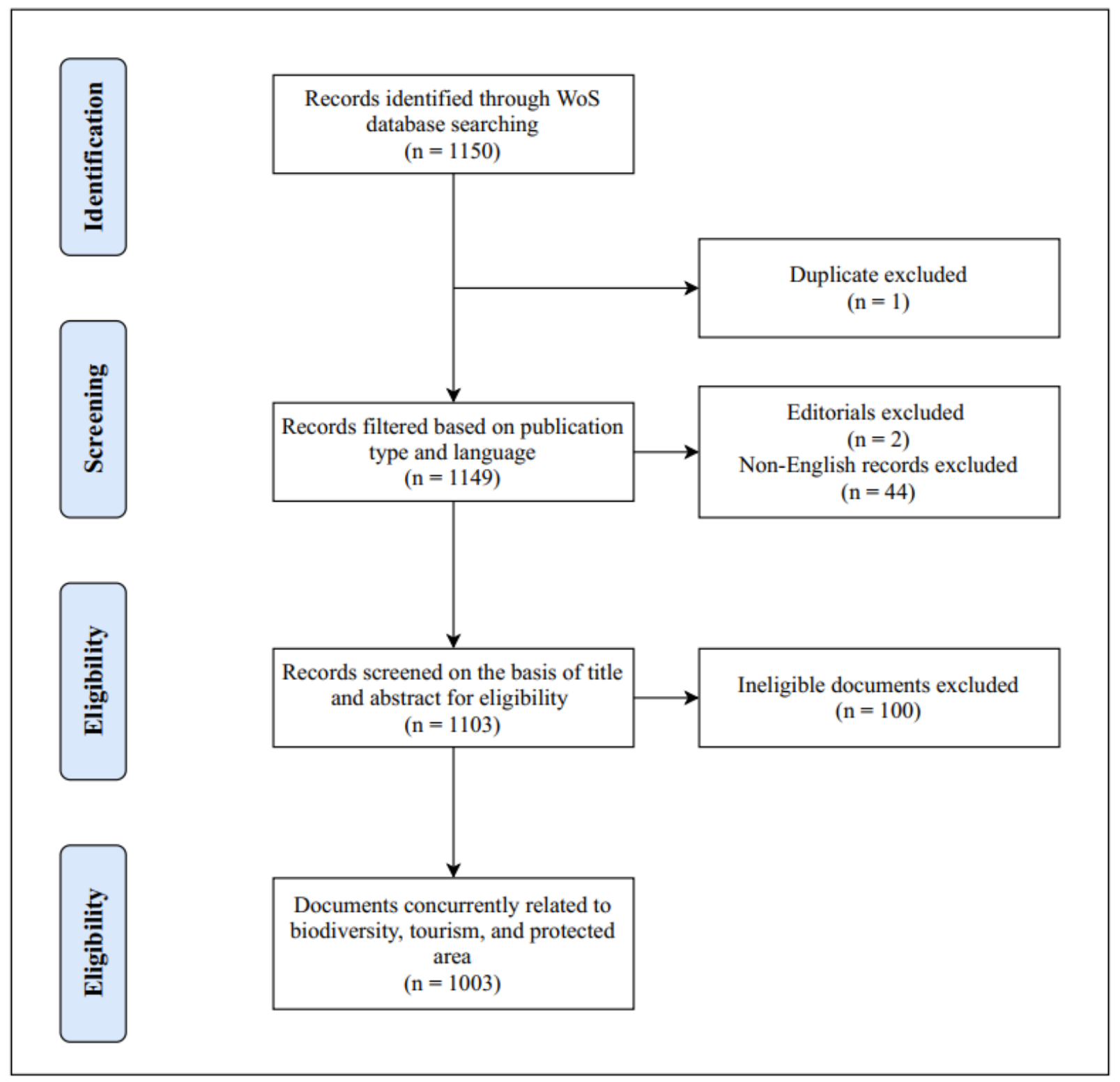

Figure 1: PRISMA flow diagram of eligible document identification

First of all, a duplicate among the collection was removed. We considered all types of documents, including articles, reviews, books, book chapters, and proceedings as scientific output, except for editorials, because editorials are usually for viewpoint and opinion sharing. Non-English documents were also excluded. The authors later screened each article's title and abstract to make sure the given document fell into the scope of this study. Any ambiguous 
documents were screened again with full-text for accuracy. In the end, 1003 papers were eligible for further analysis.

\subsection{Data analysis}

To estimate the impact of Aichi Biodiversity Targets on scientific productivity, quality, and collaboration in the interdisciplinary topic regarding biodiversity and tourism, the Bayesian analysis was utilized for several reasons. First, the frequentist approach is currently facing heavy criticism for the reproducibility crisis. The sample-to-sample variability of the $p$-value induces the crisis, and some inappropriate practices capitalizing the shortfall of $p$-value are conducted, like stargazing, $p$-hacking, and HARKing (Editorial, 2017; Halsey, Curran-Everett, Vowler, \& Drummond, 2015; Q. H. Vuong, Ho, \& La, 2019). Unlike frequentist statistics, Bayesian estimation simultaneously comprises priors and likelihood (data), allowing integrating previous knowledge and continuously updating evidence. Thanks to this updating feature, future studies assessing the effects of Aichi Biodiversity Targets on biodiversity scientific development could employ this study's findings as prior knowledge (McElreath, 2020). However, the priors' function is often criticized for making the statistical estimation subjectively biased when there are no prior knowledge and evidence. Still, the criticism could be lessened by setting priors as 'uninformative' (Gill, 2014), which is normal distribution at $\mu=0$ and $\sigma=10$ (Q.-H. Vuong, La, Nguyen, Ho, Tran, et al., 2020). Besides, the flexibility in model fitting and precise estimation when the number of observations is small are other advantages of the Bayesian approach.

Overall, the dataset for Bayesian estimation included the scientific output, citations, and international collaboration of 112 countries in both periods before and after Aichi, which made up 224 observations. Any country that published at least one publication in either the period 
before or after Aichi was selected. We added three countries that published scientific documents during 1991-2010 but none during 2011-2020 into the dataset. All the Bayesian computations were performed using five variables (see Table 1). While the "Productivity" variable represents the average publications per year of a country during the 1991-2010 or 2011-2020, the "Quality" variable represents a country's sum of all papers' average citations during two periods. The only binary variable is "Aichi." A country was coded as 1 if its statistics were during the 2011-2020 and 0 if its statistics were 1991-2010.

Table 1: Variables

\begin{tabular}{|c|c|c|c|}
\hline Variables & Name & Data Type & Description \\
\hline Productivity & $\begin{array}{l}\text { Countries' } \\
\text { scientific } \\
\text { productivity }\end{array}$ & Continuous & $\begin{array}{l}\text { Countries' scientific productivity that is } \\
\text { measured by the annual publications in a } \\
\text { given period }\end{array}$ \\
\hline Quality & $\begin{array}{c}\text { Countries' } \\
\text { scientific quality }\end{array}$ & Continuous & $\begin{array}{l}\text { Countries' scientific quality that is measured } \\
\text { by the sum of citations normalized by year in } \\
\text { a given period }\end{array}$ \\
\hline Collaboration & $\begin{array}{l}\text { Countries' } \\
\text { scientific } \\
\text { collaboration }\end{array}$ & Continuous & $\begin{array}{l}\text { Countries' scientific collaboration that is } \\
\text { measured by the number of international } \\
\text { collaborations in a given period }\end{array}$ \\
\hline Aichi & $\begin{array}{c}\text { Aichi Biodiversity } \\
\text { Targets }\end{array}$ & Binary & $\begin{array}{l}\text { Whether a country's statistics are before or } \\
\text { after the Aichi Biodiversity Targets (Before } \\
\qquad=0 \text { and After }=1 \text { ) }\end{array}$ \\
\hline
\end{tabular}


There were two steps for assessing the changes in countries' scientific productivity, quality, and collaboration after the Aichi Biodiversity Targets. First, descriptive statistics regarding the global productivity/quality/international collaboration by geographical regions were presented. Then, the Bayesian regression analysis was applied for statistical estimation. When fitting the model, all coefficients' priors were set as uninformative because we obtained no prior evidence on the association between Aichi Targets and interdisciplinary research performance. It should be noted that, unlike scientific productivity and quality utilizing Bayesian analysis, the coauthorship network was performed to visually examine the difference in international collaboration before and after Aichi.

To estimate the association between international collaboration and productivity/quality, Bayesian regression analysis was also applied. Nevertheless, the estimation was performed using two separate datasets for assessing how the association strength changed after the Aichi. The first dataset ranged from 1991 to 2010, while the second dataset was from 2011 to 2020. Uninformative priors were also employed during model fitting. All the models were simulated using 2000 warmup samples, 5000 iterations, four Markov chains, and four cores.

As for the bibliometric analysis, co-authorship analysis is used for visualizing the collaboration network among countries. The technique is to study the interactions between two or more countries in producing scientific outputs. The function of the co-authorship network is myriad. Some of them are 1) to facilitate the assessment of cross-disciplinary research programs, 2) to support strategic planning, implementation, and monitoring research programs, and 3) to aid policy planning and innovation management (Fonseca, Sampaio, de Araújo Fonseca, \& Zicker, 2016; Reyes-Gonzalez, Gonzalez-Brambila, \& Veloso, 2016). A node represents a country in a co-authorship network, while an edge represents the collaborative link between two 
different countries. The size of a node is proportionate to the given node's total joint connections, while the thickness of an edge is proportionate to the number of links between two connected nodes. When graphing the network, only the collaborations that occurred at least three times are displayed because countries sometimes collaborated by chance rather than by intention.

Finally, the Bayesian regression analysis was conducted using the bayesvl $\mathrm{R}$ package (version 0.9.5) (La \& Vuong, 2019; Q.-H. Vuong, La, Nguyen, Ho, Ho, et al., 2020) and following protocol introduced by Q.-H. Vuong, La, Nguyen, Ho, Tran, et al. (2020) for studying social sciences, while the co-authorship network was performed using the bibliometrix $\mathrm{R}$ package (version 3.3) (Aria \& Cuccurullo, 2017). For scientific transparency, the study's methodological limitations are presented in the Discussion following Q.-H. Vuong (2020) recommendations.

\section{Results}

The scientific output during 2011-2020 (778 documents) is almost triple the output during 19912010 (225 records). Collaborative activities have become more prevalent since 2011, as shown through the higher number of authors, authors per document, collaboration index, and a lower percentage of single-authored papers (see Table 2).

Table 2: Overview of scientific performance during 1991-2010 and 2011-2020

\begin{tabular}{|l|c|c|}
\hline & $\mathbf{1 9 9 1 - 2 0 1 0}$ & $\mathbf{2 0 1 1 - 2 0 2 0}$ \\
\hline \multirow{2}{*}{ Number of documents } & 189 articles & 715 articles \\
& 18 proceedings & 37 proceedings \\
& 16 reviews & 26 reviews \\
\hline
\end{tabular}




\begin{tabular}{|c|c|c|}
\hline & 2 books & \\
\hline Number of authors & 612 & 2667 authors \\
\hline Authors per document & 2.72 & 3.43 \\
\hline Single-authored documents & 71 & 3.76 \\
\hline Collaboration index & 3.53 & \\
\hline Note: The number of documents in 2020 is only counted until 31 & st July. \\
\hline
\end{tabular}

\subsection{Scientific output}

\subsubsection{Descriptive analysis}

At first glance, it can be seen that the global scientific output increased dramatically after the Aichi Biodiversity Targets. The number of countries participating in the scientific activities regarding biodiversity and tourism in protected areas also rose significantly, except for Central America (see Figure 2). Africa (15 new countries), Europe (15), and Asia (14) were three continents in which there was the highest number of new countries researching this topic. Despite the significant progress, the general coverage of this topic was still relatively low, with only $42.97 \%$ (107/249) of the total countries during 2011-2020 and 44.98\% (112/249) during 1991-2020. After the implementation of Aichi Targets, Europe (63.46\%) and Asia (52\%) were two continents with the most significant coverage, whereas Oceania (17.24\%) and LAC (26.92\%) obtained the lowest, respectively. Nevertheless, it should be noted that most countries in Oceania (65.52\%) are small island developing states (SIDS), so its low ratio of participation in interdisciplinary research, which requires massive costs, is comprehendible. 
$\square 1991--2010 \quad \square 2011-2020$

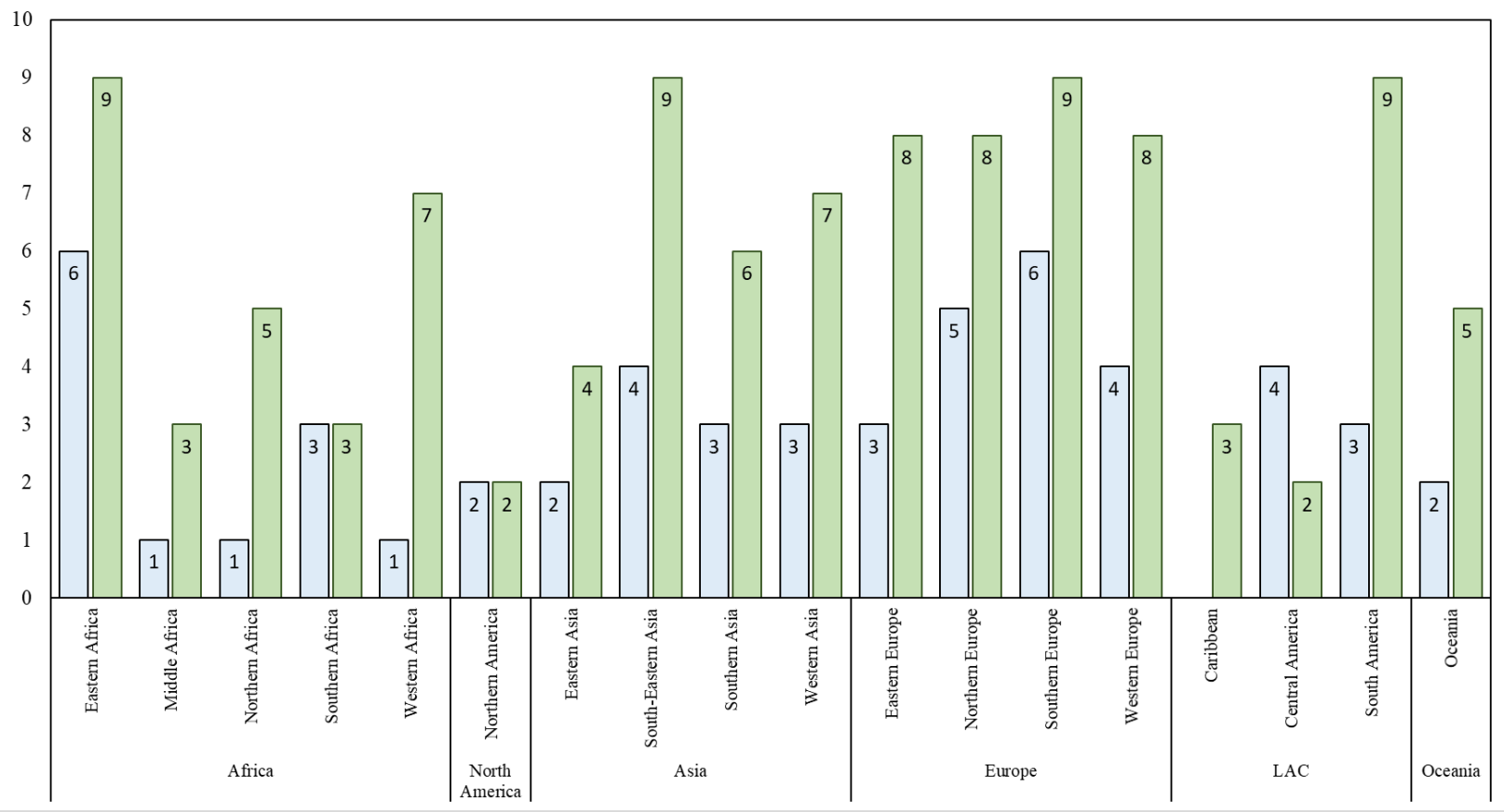

Figure 2: The number of countries researching by regions

Among the five continents, Europe contributed the highest number of documents in both periods 1991-2010 and 2011-2020, and its global share of scientific output increased from $31.70 \%$ to $35.75 \%$ (see Table 3). Even though the production of North-European countries declined by $4.70 \%$, the growth impulse of Europe derived from other sub-regions, like Southern Europe (by 4.32\%), Eastern Europe (2.46\%), and Western Europe (1.82\%). Another remarkable decline in the global share of scientific output among developed regions was observed in Northern America, the second most productive region in terms of publications, with a reduction of $-10.19 \%$.

The scientific output in LAC is worth concerning. Nature-based tourism in this region has been increasing in the last several years due to the splendid natural sceneries and rich ecosystems 
in the area (Balmford et al., 2009). Indeed, seven out of 35 biodiversity hotspots are geographically located within the LAC, namely: Atlantic Forest, Caribbean Islands, Cerrado, Chilean Winter Rainfall and Valdivian Forest, Mesoamerica, Tropical Andes, and TumbesChoco-Magdalena (Marchese, 2015). In the last decade, the LAC's global share of scientific output changed modestly by $0.34 \%$ compared to the tourism and biodiversity resources it is holding. Most remarkably, Central America's decline in the total number of publications and countries doing research could be spotted.

Table 3: Scientific output by regions during 1991-2010 and 2011-2020

\begin{tabular}{|c|c|c|c|c|c|c|}
\hline \multirow{2}{*}{ Continent } & \multirow{2}{*}{ Region $^{a}$} & \multicolumn{2}{|c|}{$\begin{array}{l}1991-2010 \\
(N=287)^{b}\end{array}$} & \multicolumn{2}{|c|}{$\begin{array}{l}2011-2020^{c} \\
(N=1,261)^{b}\end{array}$} & \multirow{2}{*}{$\begin{array}{l}\text { Global } \\
\text { share } \\
\text { change }\end{array}$} \\
\hline & & Frequency & $\begin{array}{c}\text { Frequency } \\
(\%)\end{array}$ & Frequency & $\begin{array}{c}\text { Frequency } \\
(\%)\end{array}$ & \\
\hline \multirow{5}{*}{ Africa } & Eastern Africa & 16 & $5.57 \%$ & 44 & $3.49 \% \downarrow$ & $-2.08 \%$ \\
\hline & Middle Africa & 1 & $0.35 \%$ & 7 & $0.56 \% \uparrow$ & $0.21 \%$ \\
\hline & Northern Africa & 1 & $0.35 \%$ & 10 & $0.79 \% \uparrow$ & $0.44 \%$ \\
\hline & Southern Africa & 17 & $5.92 \%$ & 77 & $6.11 \% \uparrow$ & $0.19 \%$ \\
\hline & Western Africa & 1 & $0.35 \%$ & 16 & $1.27 \% \uparrow$ & $0.92 \%$ \\
\hline America & Northern America & 80 & $27.87 \%$ & 222 & $17.61 \% \downarrow$ & $-10.26 \%$ \\
\hline \multirow{4}{*}{ Asia $^{d}$} & Eastern Asia & 12 & $4.18 \%$ & 91 & $7.22 \% \uparrow$ & $3.04 \%$ \\
\hline & South-Eastern Asia & 6 & $2.09 \%$ & 41 & $3.25 \% \uparrow$ & $1.16 \%$ \\
\hline & Southern Asia & 10 & $3.48 \%$ & 54 & $4.28 \% \uparrow$ & $0.80 \%$ \\
\hline & Western Asia & 9 & $2.79 \%$ & 27 & $2.14 \% \downarrow$ & $-0.65 \%$ \\
\hline \multirow{4}{*}{ Europe } & Eastern Europe & 5 & $1.74 \%$ & 53 & $4.20 \% \uparrow$ & $2.46 \%$ \\
\hline & Northern Europe & 44 & $15.33 \%$ & 134 & $10.63 \% \downarrow$ & $-4.70 \%$ \\
\hline & Southern Europe & 19 & $6.62 \%$ & 138 & $10.94 \% \uparrow$ & $4.32 \%$ \\
\hline & Western Europe & 23 & $8.01 \%$ & 124 & $9.83 \% \uparrow$ & $1.82 \%$ \\
\hline \multirow{3}{*}{$\mathbf{L A C}^{\mathrm{e}}$} & Caribbean & & & 7 & $0.56 \% \uparrow$ & $0.56 \%$ \\
\hline & Central America & 10 & $3.48 \%$ & 20 & $1.59 \% \downarrow$ & $-1.89 \%$ \\
\hline & South America & 10 & $3.48 \%$ & 65 & $5.15 \% \uparrow$ & $1.67 \%$ \\
\hline
\end{tabular}




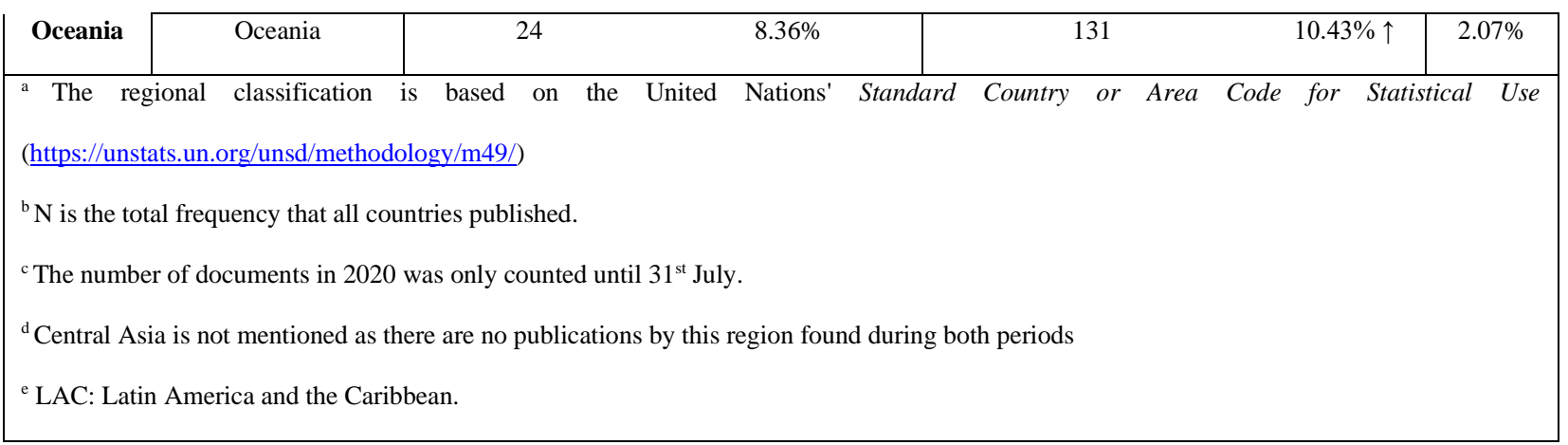

\subsubsection{Bayesian analysis}

For testing whether the Aichi Biodiversity Targets results in higher interdisciplinary scientific output on tourism and biodiversity, the following model 1 is estimated using a Bayesian linear regression:

$$
\text { Productivity } \sim \text { Aichi }
$$

The posterior coefficients of model 1 are shown in Table S1. The effective sample size (n_eff) of all coefficients is larger than 1000, and the Gelman Shrink Factor (Rhat) equals 1 (if Rhat $>1.1$, the model is not convergent). Visually, the trace plots also demonstrate stationary and goodmixing chains (see Figure 3.a), and thus, the Markov property is held. The autocorrelation of the simulated samples of the coefficient "Aichi_Productivity" was eliminated after finite steps (see Figure 3.b), while the Gelman shrink factor dropped swiftly to 1.0 during the warmup period (see Figure 3.c). A positive coefficient $\left(\beta_{\text {Aichi_Productivity }}=1.00\right)$ with a low standard deviation at around 0.22 suggests that global productivity at the national level increased after the Aichi Biodiversity Targets. The posterior distribution demonstrated in Figure 3.d is located entirely on the positive side of the $\mathrm{x}$-axis, which reconfirms the positive impact of Aichi Biodiversity Targets on interdisciplinary research productivity regarding tourism and biodiversity at the global scale. 
a)

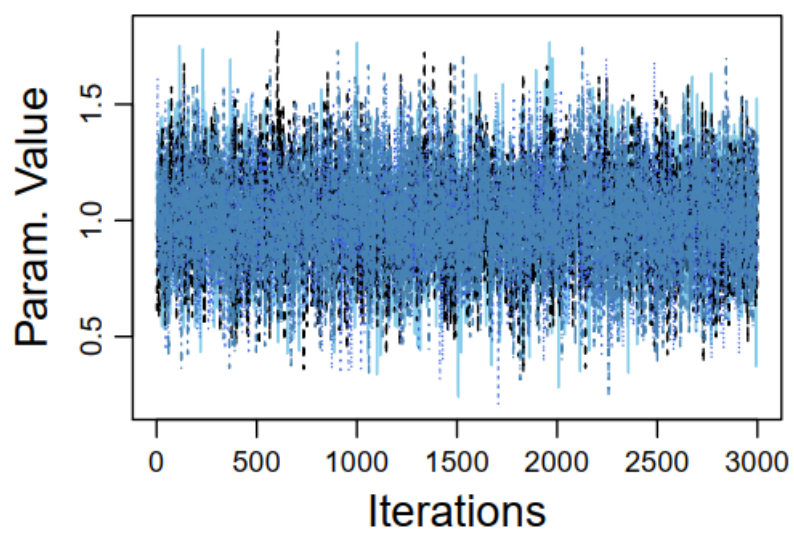

c)

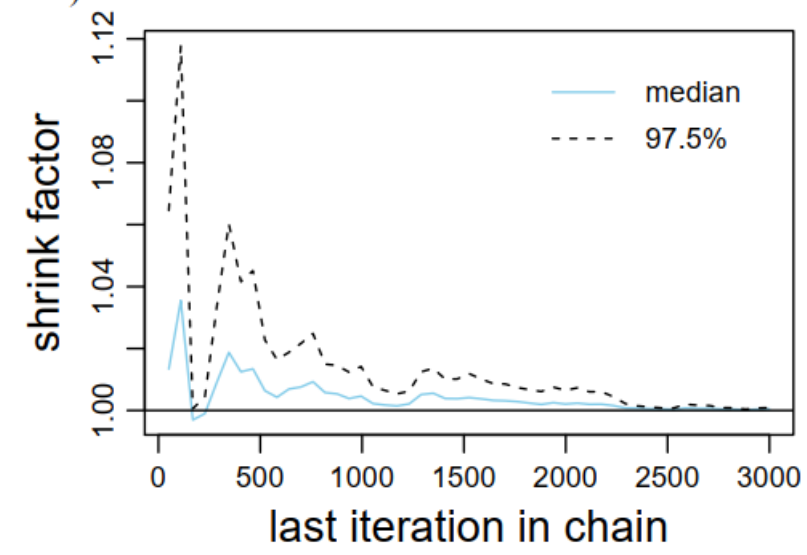

b)

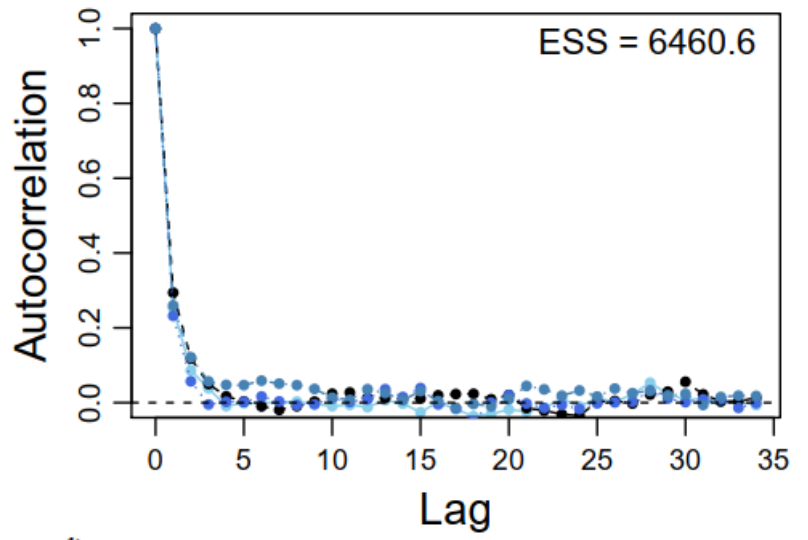

d)

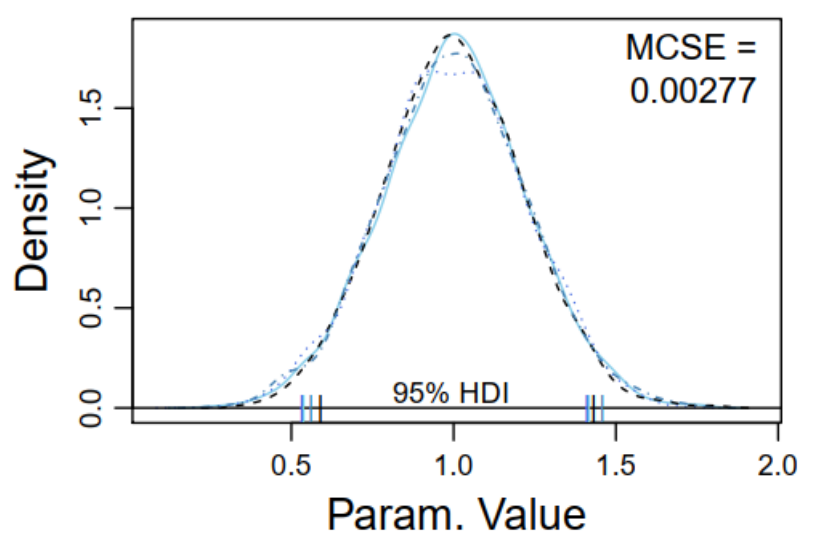

Figure 3: a) Trace plot, b) Autocorrelation plot, c) Gelman plot, and d) parameter distribution of $\beta_{\text {Aichi_Productivity }}$

\subsection{Scientific influence}

\subsubsection{Descriptive analysis}

The number of citations can be used to measure scientific influence and quality interchangeably (Sahel, 2011). In Table 4, the difference between the total average citations per year (or adjusted citations) by regions during the 1991-2010 and 2011-2020 is shown. Overall, the altering trend of scientific quality after the Aichi Targets was analogous to that of scientific productivity. On the one hand, despite the increase in the total adjusted citations after 2010, Northern America's 
and Northern Europe's global share dropped dramatically by $8.97 \%$ and $3.19 \%$, respectively. On the other hand, the three fastest-growing regions in the global share of adjusted citations were Southern Europe (by 5.21\%), Southern Africa (by 3.19\%), and Eastern Asia (by 2.53\%). Notably, in the LAC, the scientific influence/quality of South American countries rose substantially by $2.35 \%$, but the decline by $1.77 \%$ of Central American countries was witnessed.

Table 4: Scientific influence/quality by regions during 1991-2010 and 2011-2020

\begin{tabular}{|c|c|c|c|c|c|c|}
\hline \multirow{2}{*}{ Continent } & \multirow{2}{*}{ Region $^{a}$} & \multicolumn{2}{|c|}{$\begin{array}{c}1991-2010 \\
(\mathrm{~N}=\mathbf{8 9 5 . 8 1})^{b}\end{array}$} & \multicolumn{2}{|c|}{$\begin{array}{c}2011-2020^{\mathrm{c}} \\
(\mathrm{N}=2,791.26)^{\mathrm{b}}\end{array}$} & \multirow{2}{*}{$\begin{array}{l}\text { Global } \\
\text { share } \\
\text { change }\end{array}$} \\
\hline & & Adj. citation & $\begin{array}{c}\text { Adj. citation } \\
\qquad(\%)\end{array}$ & Adj. citation & $\begin{array}{c}\text { Adj. citation } \\
(\%)\end{array}$ & \\
\hline \multirow{5}{*}{ Africa } & Eastern Africa & 35.09 & $3.92 \%$ & 81.21 & $2.91 \% \downarrow$ & $-1.01 \%$ \\
\hline & Middle Africa & 0.27 & $0.03 \%$ & 17.61 & $0.63 \% \uparrow$ & $0.60 \%$ \\
\hline & Northern Africa & 1.17 & $0.13 \%$ & 12.98 & $0.46 \% \uparrow$ & $0.33 \%$ \\
\hline & Southern Africa & 35.22 & $3.93 \%$ & 198.64 & $7.12 \% \uparrow$ & $3.19 \%$ \\
\hline & Western Africa & 0.00 & $0.00 \%$ & 33.06 & $1.18 \% \uparrow$ & $1.18 \%$ \\
\hline America & Northern America & 276.13 & $30.82 \%$ & 609.83 & $21.85 \% \downarrow$ & $-8.97 \%$ \\
\hline \multirow{4}{*}{ Asia $^{d}$} & Eastern Asia & 22.34 & $2.49 \%$ & 140.18 & $5.02 \% \uparrow$ & $2.53 \%$ \\
\hline & South-Eastern Asia & 5.59 & $0.62 \%$ & 39.31 & $1.41 \% \uparrow$ & $0.79 \%$ \\
\hline & Southern Asia & 24.76 & $2.76 \%$ & 69.49 & $2.49 \% \downarrow$ & $-0.27 \%$ \\
\hline & Western Asia & 7.89 & $0.88 \%$ & 13.29 & $0.48 \% \downarrow$ & $-0.40 \%$ \\
\hline \multirow{4}{*}{ Europe } & Eastern Europe & 4.22 & $0.47 \%$ & 24.43 & $0.88 \% \uparrow$ & $0.41 \%$ \\
\hline & Northern Europe & 171.16 & $19.11 \%$ & 437.22 & $15.66 \% \downarrow$ & $-3.45 \%$ \\
\hline & Southern Europe & 62.63 & $6.99 \%$ & 340.55 & $12.20 \% \uparrow$ & $5.21 \%$ \\
\hline & Western Europe & 112.54 & $12.56 \%$ & 273.87 & $9.81 \% \downarrow$ & $-2.75 \%$ \\
\hline \multirow{3}{*}{$\mathbf{L A C}^{\mathrm{e}}$} & Caribbean & 0.00 & $0.00 \%$ & 10.73 & $0.38 \% \uparrow$ & $0.38 \%$ \\
\hline & Central America & 21.97 & $2.45 \%$ & 18.86 & $0.68 \% \downarrow$ & $-1.77 \%$ \\
\hline & South America & 19.30 & $2.16 \%$ & 125.96 & $4.51 \% \uparrow$ & $2.35 \%$ \\
\hline Oceania & Oceania & 95.53 & $10.66 \%$ & 344.03 & $12.33 \% \uparrow$ & $1.67 \%$ \\
\hline $\begin{array}{l}\text { a The re } \\
\text { (https://uns }\end{array}$ & onal classification & $\begin{array}{l}\text { based on the } \\
y / m 49 /)\end{array}$ & Nations' & untry or & ode for Stc & ical Use \\
\hline
\end{tabular}


${ }^{\mathrm{b}} \mathrm{N}$ is the total adjusted citations that all countries received.

${ }^{\mathrm{c}}$ The adjusted citations in 2020 was only counted until $31^{\text {st }}$ July.

${ }^{\mathrm{d}}$ Central Asia is not mentioned as there are no publications by this region found during both periods

${ }^{\mathrm{e}} \mathrm{LAC}$ : Latin America and the Caribbean.

\subsubsection{Bayesian analysis}

The Bayesian analysis for estimating the relationship between Aichi Biodiversity Targets and scientific quality was conducted similarly with the above procedure. Therefore, the following formula was utilized:

$$
\text { Quality } \sim \text { Aichi }
$$

The estimated posteriors are presented in Table S2. The n_eff was larger than 1000, and the Rhat equaled 1, so the model could be considered to acquire well convergence and satisfy the Markov property. The trace plots illustrated in Figure 4.a also confirmed that all Markov chains were not divergent. The coefficient's distribution of the relationship between Aichi Targets and scientific quality was positive $\left(\beta_{\text {Aichi_Productivity }}=7.50\right)$, which indicates that the global scientific quality/influence at the national level increased after the Aichi Biodiversity Targets. Even though a minor part of the coefficient's posterior distribution fell into the negative side of the x-axis, the Aichi Biodiversity Targets were also considered to positively affect the global scientific quality with 95\% of the Highest Posterior Distribution Intervals (see Figure 4.d). 
a)

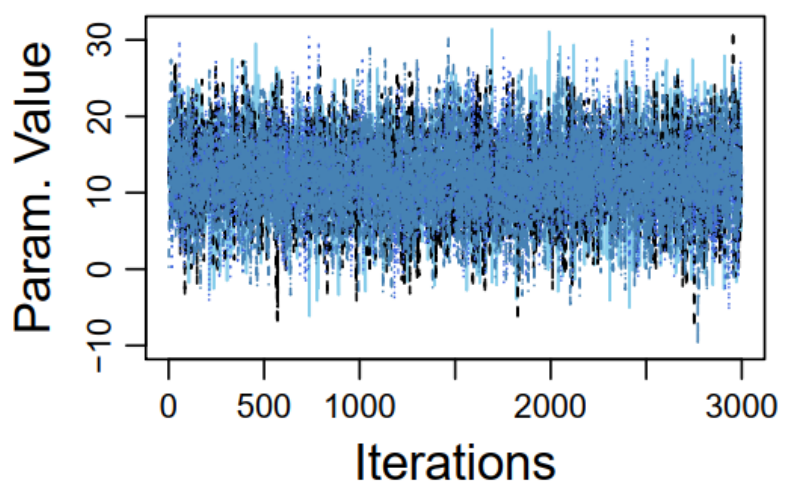

c)

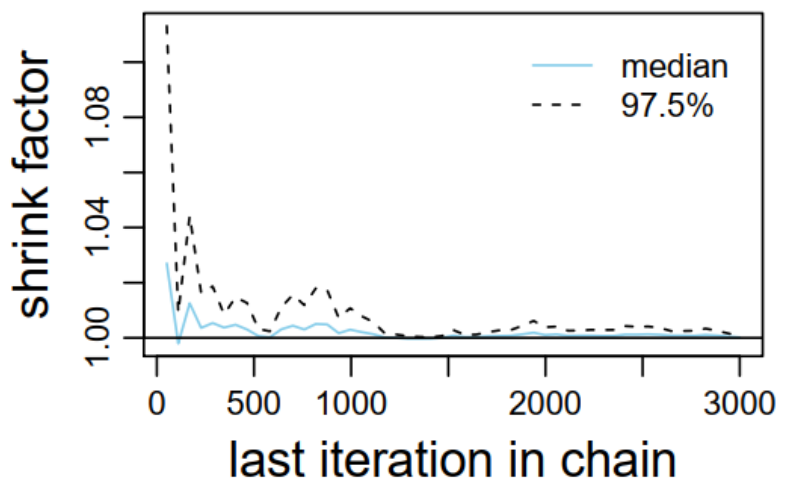

b)

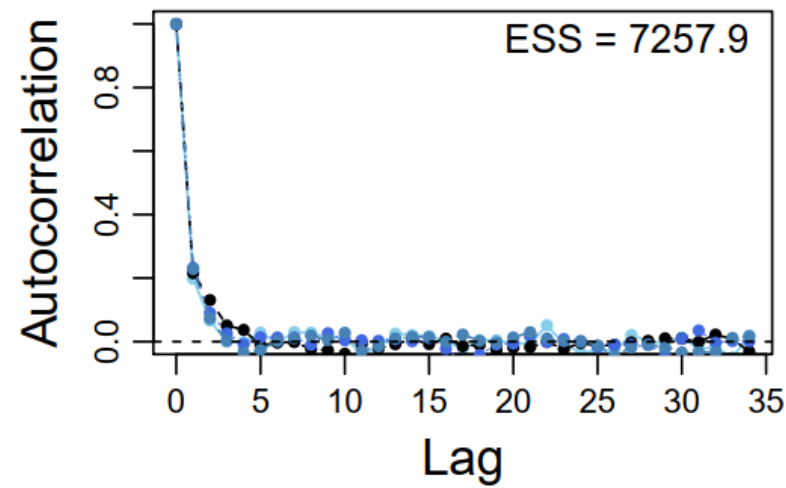

d)

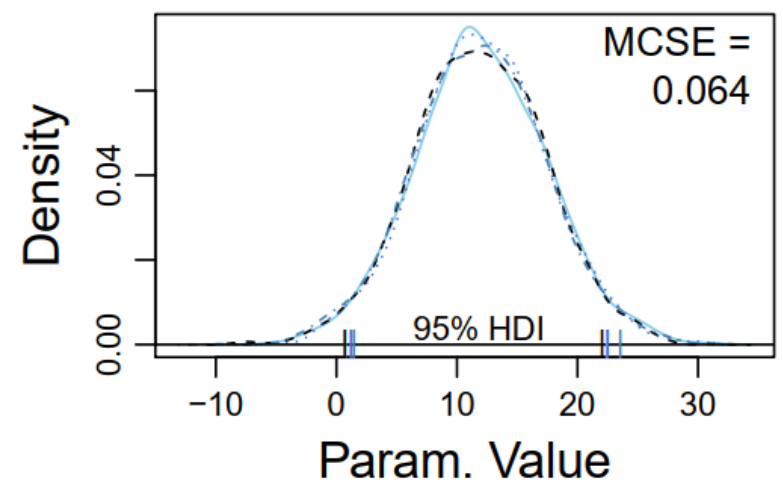

Figure 4: a) Trace plot, b) Autocorrelation plot, c) Gelman plot, and d) parameter distribution of $\beta_{\text {Aichi_Quality }}$

\subsection{Collaboration}

\subsubsection{Descriptive analysis}

International collaboration has long been acknowledged as a shortcut for peripheral countries to improve their scientific capacity. For that reason, sharing and transferring knowledge are fundamental components of the Aichi Target 19. Here, we presented how the global collaboration network had changed since the implementation of Aichi Biodiversity Targets. 
Table 5: Scientific collaboration by regions during the 1991-2010 and 2011-2020

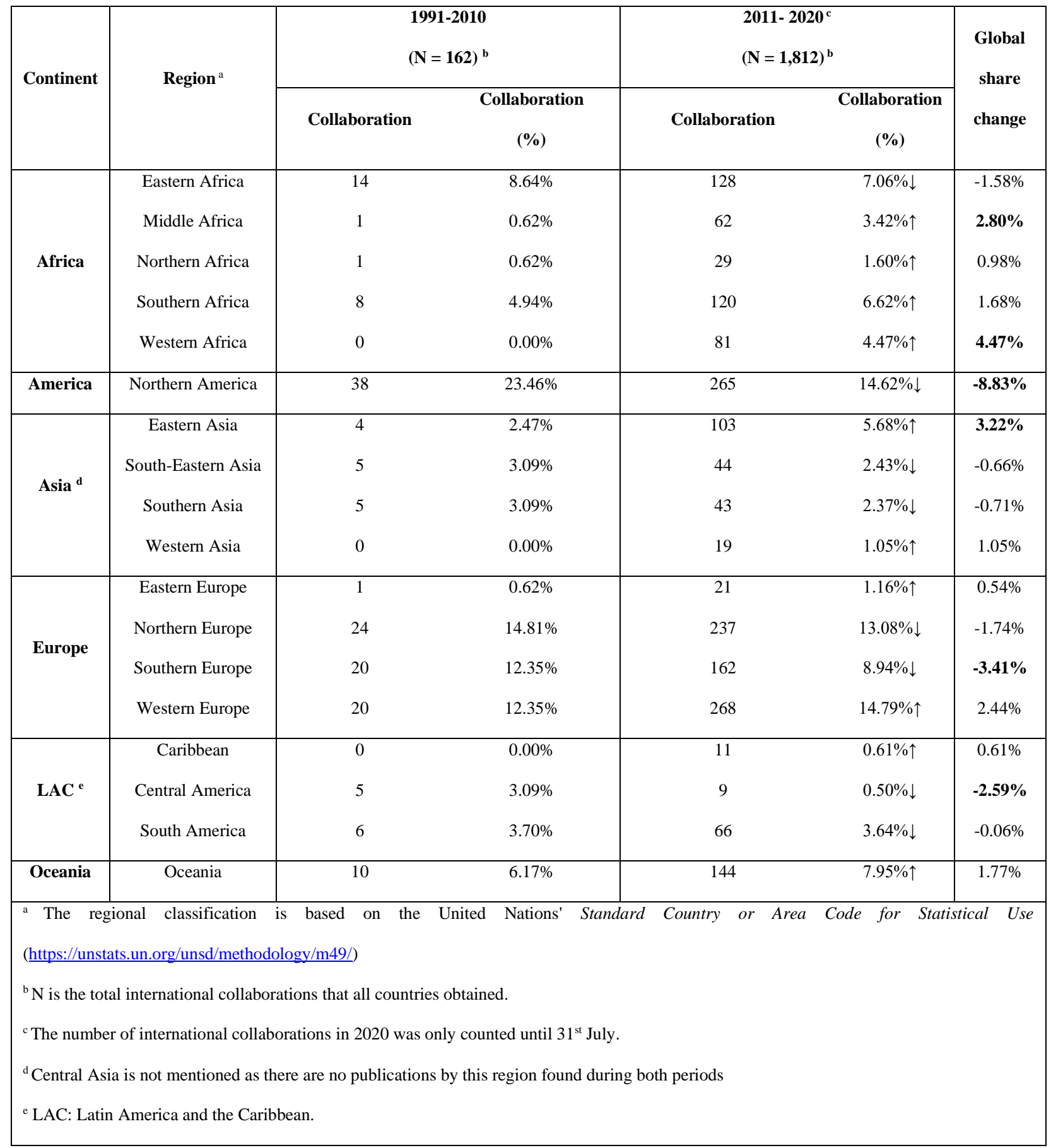

Most of the countries' international collaboration patterns were similar to those of countries' scientific productivity and quality. Expressly, the global share of international collaborations of countries in Northern America (by 8.83\%) and Northern Europe (by 1.74\%) 
declined after the Aichi Targets, despite their elevation in the collaboration quantity (see Table 5). Also, the decrease of Central American countries' global share in the number of collaborations was observed after 2010. Nonetheless, the substantial rise in the global share of international collaborations of Western Africa and the significant drop of Southern Europe was different from the patterns of countries' scientific productivity and quality.

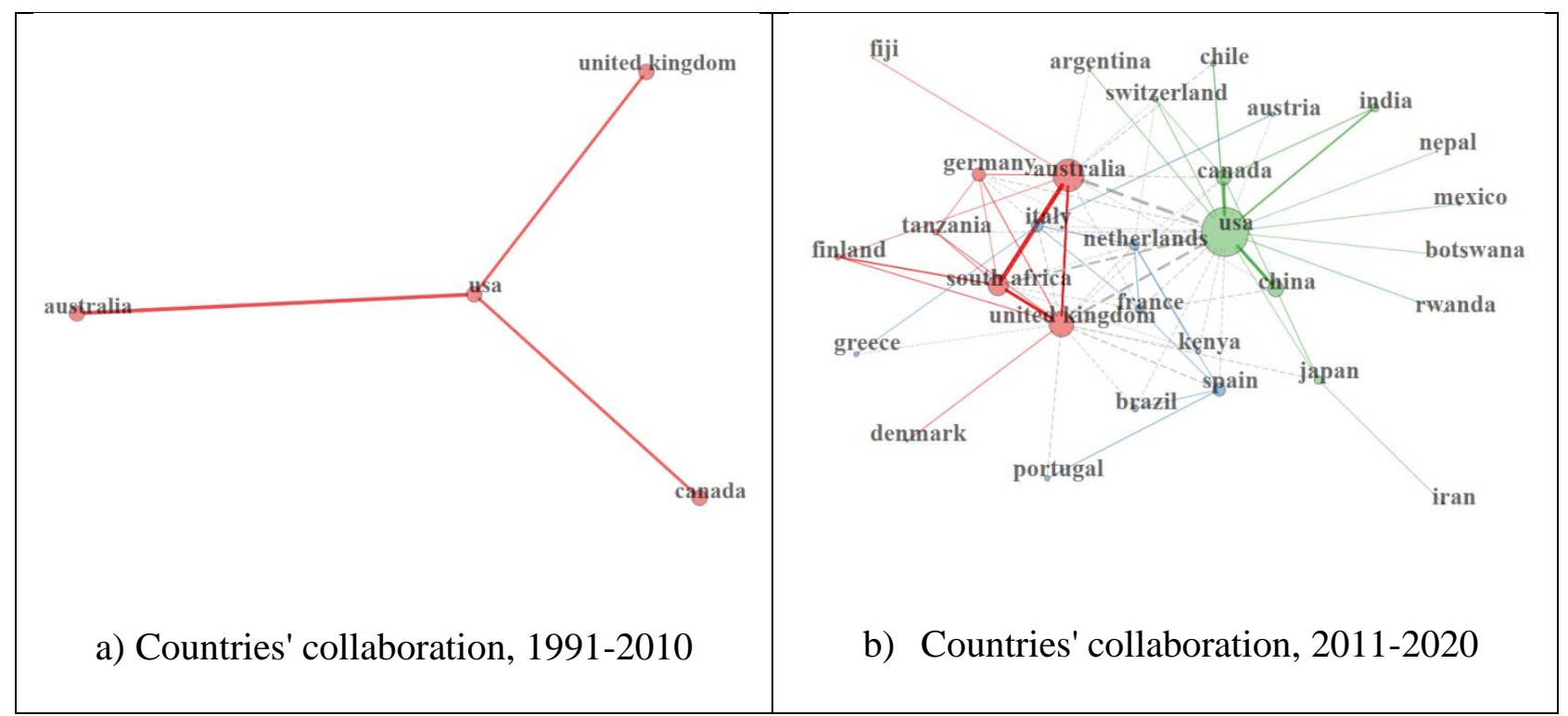

Figure 5: The collaboration networks across countries during the 1991-2010 and 2011-2020

For better examining the alteration after the Aichi Targets, we visualize exclusively the connection between two countries that have at least three collaborations together. Figure 5 illustrates the collaborative research networks across countries during 1991-2010 and 2011-2020. Before implementing Aichi Biodiversity Targets, joint activities were scattered, and they were wholly among Western countries, like the United States, the United Kingdom, Australia, and Canada. Nevertheless, since 2011, the network participants had expanded rapidly in terms of quantity and diversity. Still, only 30 countries were found to frequently collaborated (at least 
three times). In contrast, most countries published in this field (a total of 105 countries during 2011-2020) had either no scientific collaboration or no frequent collaborative link.

\subsubsection{Bayesian analysis}

In this sub-section, we did not replicate the estimation with Aichi being the predictor variable, but we examined the association between Collaboration and Productivity/Quality. The international collaboration's impacts on scientific productivity and quality were justified and compared between 1991-2010 and 2011-2020. The following models were estimated for that purpose:

$$
\begin{aligned}
& \text { Productivity } \sim \text { Collaboration } \\
& \text { Quality } \sim \text { Collaboration }
\end{aligned}
$$

While model 3 was to examine the association between countries' international collaboration and scientific productivity, model 4 was to investigate the association between countries' international collaboration and scientific quality. The posterior estimates of both models are displayed in Table 6. All the coefficients' n_eff and Rhat showed that all Markov chains were well convergent.

In general, international collaboration was found to have a positive effect on countries' productivity and quality, but there is a distinction between the two associations. While the international collaboration obtained almost similar impact on productivity $\left(\beta_{\text {Collaboration_Productivity_before }}=0.09\right.$ vs $\left.\beta_{\text {Collaboration_Productivity_after }}=0.07\right)$ during both periods 1991-2010 and 2011-2020, the effect strength of international collaboration on scientific 
quality between two periods was dissimilar. Specifically, the effect of international collaboration on scientific quality during 1991-2010 was three-fold more substantial than during 2011-2020 $\left(\beta_{\text {Collaboration_Quantity_before }}=6.91\right.$ vs $\left.\beta_{\text {Collaboration_Quantity_after }}=2.05\right)$. Such a distinction between two associations might result from the trilemma between quantity, quality, and cost, which we would explain in the Discussion.

Table 6: Estimation of scientific productivity and quality/influence against international collaboration

\begin{tabular}{|c|c|c|c|c|c|}
\hline \multicolumn{6}{|c|}{ Model 3: Scientific productivity as a dependent variable } \\
\hline Period & Variables & Mean & SD & n_eff & Rhat \\
\hline \multirow{2}{*}{$1991-2010$} & Constant & -0.01 & 0.01 & 8137 & 1 \\
\hline & Collaboration_Productivity_before & 0.09 & 0.00 & 9752 & 1 \\
\hline \multirow{2}{*}{ 2011-2020 } & Constant & -0.08 & 0.01 & 7521 & 1 \\
\hline & Collaboration_Productivity_after & 0.07 & 0.00 & 9810 & 1 \\
\hline \multicolumn{6}{|c|}{ Model 4: Scientific quality as a dependent variable } \\
\hline Period & Variables & Mean & SD & n_eff & Rhat \\
\hline \multirow{2}{*}{$1991-2010$} & Constant & -1.98 & 0.84 & 8725 & 1 \\
\hline & Collaboration_Quality_before & 6.91 & 0.21 & 8524 & 1 \\
\hline \multirow{2}{*}{$2011-2020$} & Constant & -8.11 & 2.23 & 8255 & 1 \\
\hline & Collaboration_Quality_after & 2.05 & 0.07 & 8174 & 1 \\
\hline
\end{tabular}




\section{Discussion}

The current study attempted to examine how interdisciplinary research regarding tourism and biodiversity had changed since the Aichi Biodiversity Targets using the Bayesian linear regression and social network mapping. The analyses were based on 1,003 eligible documents extracted from the WoS database.

Our descriptive findings suggested that countries' scientific productivity, quality, and international collaboration had grown swiftly for the last decade. Bayesian statistics also confirmed the effectiveness of Aichi Biodiversity Targets on the cultivation of interdisciplinary knowledge, mainly between tourism and biodiversity $\left(\beta_{\text {Aichi_Productivity }}=1.00\right.$ and $\left.\beta_{\text {Aichi_Quality }}=11.96\right)$. Eastern Asia's scientific enhancement was the most notable because of its uniform improvements in all categories (by $3.04 \%$ in productivity, by $2.53 \%$ in quality, and by $3.22 \%$ in collaboration). China and Japan were two countries that substantially constituted the improvement of Eastern Asia. On the contrary, Northern America's and Northern Europe's global share declined in all aspects, hinting at the diminishing dependence on few countries for knowledge generation and sharing.

Despite the progress in scientific productivity and quality in multiple countries, the low and declining productivity, quality, and collaboration in the LAC were critical. This result supports the argument of Tydecks et al. (2018) that "major research deficits occur in regions with disproportionately high biodiversity as well as a high share of threatened species." The substandard performance of LAC countries after the Targets could be the results of research focus directed to biodiversity and climate change, poor research leadership, international collaboration bias towards a few countries, and low funding capacity (Ahrends et al., 2011; Dangles et al., 2016; World Bank Group, 2012). Given that the nature-based tourism sector is 
expanding and one-fifth of biodiversity hotspots are located in that region, the mutual impacts between tourism and biodiversity demand more attention. Nature-based tourism is a doubleedged tool. Appropriate use might contribute to biodiversity conservation financing and socioeconomic development, but insufficient comprehension of tourism and biodiversity might also result in catastrophic consequences (Hall, 2010b). Thus, the LAC research focus should be revised so that tourism can be put into perspective like it was in the Aichi Biodiversity Targets.

Besides improving scientific productivity, quality, and collaboration, the number of countries conducting interdisciplinary research on biodiversity and tourism also surged by two-fold after the Aichi Targets (from 53 to 107 countries). Africa (by 15 countries), Europe (by 15 countries), and Asia (by 14 countries) were three continents that observed a tremendous increase. Still, this research topic's global coverage was inadequate that more than half of the countries on Earth $(57.02 \%)$ had not conducted any interdisciplinary study about biodiversity and tourism.

Usually, this topic's low prevalence can be amended through international collaboration, which helps reduce cost, exchange knowledge, and acquire more global funding opportunities. Our findings also confirmed this assumption. We found that countries' number of collaborations is positively associated with scientific productivity $\left(\beta_{\text {Collaboration_Productivity_before }}=0.09 \mathrm{vs}\right.$ $\left.\beta_{\text {Collaboration_Productivity_after }}=0.07\right)$ and quality $\left(\beta_{\text {Collaboration_Quantity_before }}=6.91\right.$ vs $\beta_{\text {Collaboration_Quantity_after }}=2.05$ ) regardless of the periods before or after the Aichi Targets. Nevertheless, the correlation patterns revealed the tradeoffs of quantity, quality, and cost in scientific production. That is, only two out of three targets can be achieved at a time (Pauly, 2011).

O the one hand, the international collaboration had an almost similar effect on the scientific productivity during 1991-2010 and 2011-2020, so we assumed that scientific quantity induced by 
a unit of international collaboration was unchanged after the Aichi Targets. On the other hand, the effect of international collaboration on scientific quality after the Aichi dropped significantly, which suggested that the scientific quality induced by a unit of international collaboration declined substantially. This decline was potentially the consequence of more developing countries getting involved in the global collaboration network. Because of the low scientific funding and capacity of developing countries (Q.-H. Vuong, 2018), the effectiveness and efficiency of a unit of collaboration were lessened, leading to lower scientific quality while remaining the scientific output.

We would like to argue that international collaboration is not a "silver bullet" for improving scientific quantity and quality regarding interdisciplinary research, which requires a substantial amount of economic resources. Still, it is a tradeoff between quantity and quality. Especially in an era full of crises (e.g., environmental disasters and COVID-19, etc.), the global economic recession could happen at any time and make financing systems for scientific activities related to biodiversity collapse. Therefore, a breakthrough is needed to lessen the tradeoffs between quantity, quality, and cost.

The culture that holds a crucial position in human civilization and development could be a potential breakthrough. As people are inevitably influenced by cultural elements, social sciences and cultural research have been perceived as critical solutions to most global problems, like climate change (Shah, 2020; Straughan \& Dixon, 2012; Victor, 2015; Q.-H. Vuong et al., 2018; Q.-H. Vuong, Ho, et al., 2020), but the cultural aspect has been neglected in environmentalhealing endeavors. Even one of the most widely adopted systems of progressive core value by Harrison (2000) scarcely mentioned any environment-related keywords, such as "environment," "nature," "sustainability," and "biodiversity." Thus, inspired by Q. H. Vuong (2020), we would 
like to encourage policymakers, funding evaluators, and scientists to put "mindsponge" culture into perspectives.

Interdisciplinary research is evidenced to positively associate with research impact, but it is also found to be less likely to be funded (Bromham, Dinnage, \& Hua, 2016; Okamura, 2019). One of the main reasons learned from the current research is that evaluation systems are limited by narrow disciplinary views (Bromham et al., 2016). Thus, integrating a mindsponge perspective into the research evaluation system would allow interdisciplinary research being allocated more resources, which might indirectly enhance the quality and quantity of the research project.

Besides the narrow disciplinary evaluation standards, the interdisciplinary project's substantial costs are also a significant reason hindering the research quality and quantity. As interdisciplinary research requires researchers from various backgrounds to work together, investing a substantial amount of time in establishing collaborative relationships, developing a shared language, and sharping a common view from distinct perspectives are inevitable (Bromham et al., 2016). Such costs are induced by the friction of the connection between multiple viewpoints. Adopting the mindsponge culture in an interdisciplinary group would lessen the friction (Q. H. Vuong \& Napier, 2015), and eventually, reduce the cost of conducting interdisciplinary research.

Moreover, when the collaboration between researchers from developing and developed countries happen, developing-country and developed-country researchers are encouraged to acquire a proactive attitude and a mindsponge perspective, respectively, for better research impact. Developing-country researchers need to be more confident and proactively contribute to the research project as their viewpoints are indigenous knowledge (Q.-H. Vuong, 2019). At the 
same time, developed-country researchers should be more open to indigenous knowledge through a mindsponge mechanism. Ultimately, without raising the cost, the research output and quality could be improved by incorporating local or indigenous knowledge or viewpoints.

The study is not without limitations. The study was based on the bibliometric method, so the results should be combined with a qualitative approach, which is expert judgments when applied in real contexts. Moreover, the data analyzed were limited to the WoS database, so biases towards English-speaking countries are notable (Nguyen et al., 2020). The method counting the total publications and citations for proxying scientific quantity and quality was insufficient to measure the real impact of interdisciplinary research on tourism and biodiversity. Thus, future studies are encouraged to employ pragmatic data to fill in the gap of scientific impact measurement.

\section{Supplementary}

Table S1: Estimation of scientific productivity against Aichi Targets

\begin{tabular}{|c|c|c|c|c|}
\hline Variables & Mean & SD & n_eff & Rhat \\
\hline Constant & 0.12 & 0.16 & 6466 & 1 \\
\hline Aichi_Productivity & 1.00 & 0.22 & 6393 & 1 \\
\hline
\end{tabular}

Table S2: Estimation of scientific quality/influence against Aichi Targets

\begin{tabular}{|c|c|c|c|c|}
\hline & Mean & SD & n_eff & Rhat \\
\hline Constant & 10.50 & 4.20 & 6469 & 1 \\
\hline
\end{tabular}




$$
\text { Aichi_Quality }
$$

11.96

5.45

6767

\section{References}

Ahrends, A., Burgess, N. D., Gereau, R. E., Marchant, R., Bulling, M. T., Lovett, J. C., . . . Fanning, E. (2011). Funding begets biodiversity. Diversity Distributions, 17(2), 191-200.

Aria, M., \& Cuccurullo, C. (2017). bibliometrix: An R-tool for comprehensive science mapping analysis. Journal of Informetrics, 11(4), 959-975.

Balmford, A., Beresford, J., Green, J., Naidoo, R., Walpole, M., \& Manica, A. (2009). A global perspective on trends in nature-based tourism. PLoS biology, 7(6).

Balmford, A., Green, J. M., Anderson, M., Beresford, J., Huang, C., Naidoo, R., . . Manica, A. (2015). Walk on the wild side: estimating the global magnitude of visits to protected areas. PLoS Biol, 13(2), e1002074.

Baral, N., Stern, M. J., \& Bhattarai, R. (2008). Contingent valuation of ecotourism in Annapurna conservation area, Nepal: Implications for sustainable park finance and local development. Ecological Economics, 66(2-3), 218-227.

Bromham, L., Dinnage, R., \& Hua, X. (2016). Interdisciplinary research has consistently lower funding success. Nature, 534(7609), 684-687.

Bruner, A. G., Gullison, R. E., Rice, R. E., \& Da Fonseca, G. A. (2001). Effectiveness of parks in protecting tropical biodiversity. science, 291(5501), 125-128.

CBD High-Level Panel. (2014). Resourcing the Aichi Biodiversity Targets: An Assessment of Benefits, Investments and Resource needs for Implementing the Strategic Plan for Biodiversity 2011-2020. Retrieved from Montreal, Canada:

Convention on Biological Diversity. (2006). Article 2. Use of Terms. Retrieved from https://www.cbd.int/convention/articles/?a=cbd-02

Convention on Biological Diversity. (2018a). Aichi Biodiversity Targets. Retrieved from https://www.cbd.int/sp/targets/

Convention on Biological Diversity. (2018b). Decision adopted by the conference of the Parties to the Convention on Biological Diversity. (CBD/COP/DEC/14/34). Egypt: United Nations

Dangles, O., Loirat, J., Freour, C., Serre, S., Vacher, J., \& Le Roux, X. (2016). Research on biodiversity and climate change at a distance: collaboration networks between Europe and Latin America and the Caribbean. PLOS ONE, 11(6), e0157441.

Dharmaratne, G. S., Sang, F. Y., \& Walling, L. J. (2000). Tourism potentials for financing protected areas. Annals of tourism research, 27(3), 590-610.

Dudley, N., Shadie, P., \& Stolton, S. (2013). Guidelines for applying protected area management categories including IUCN WCPA best practice guidance on Recognising Protected Areas and Assigning Management Categories and Governance Types (18173713). Retrieved from Gland, Switzerland:

Editorial. (2017). Promoting reproducibility with registered reports. Nature Human Behaviour, 1(1), 0034. doi:10.1038/s41562-016-0034

Emerton, L., Bishop, J., \& Thomas, L. (2006). Sustainable Financing of Protected Areas: A global review of challenges and options: IUCN. 
Ferraro, P. J., \& Hanauer, M. M. (2011). Protecting ecosystems and alleviating poverty with parks and reserves:'win-win'or tradeoffs? Environmental and resource economics, 48(2), 269-286.

Fonseca, B. d. P. F., Sampaio, R. B., de Araújo Fonseca, M. V., \& Zicker, F. (2016). Coauthorship network analysis in health research: method and potential use. Health Research Policy and Systems, 14(1), 34.

Gill, J. (2014). Bayesian methods: A social and behavioral sciences approach (Vol. 20): CRC press.

Gössling, S. (2002). Global environmental consequences of tourism. Global environmental change, 12(4), 283-302.

Gössling, S., \& Hall, M. C. (2006). Tourism and global environmental change: Taylor \& Francis.

Hall, C. M. (2010a). Changing paradigms and global change: From sustainable to steady-state tourism. Tourism Recreation Research, 35(2), 131-143.

Hall, C. M. (2010b). Tourism and biodiversity: more significant than climate change? Journal of Heritage Tourism, 5(4), 253-266.

Halsey, L. G., Curran-Everett, D., Vowler, S. L., \& Drummond, G. B. (2015). The fickle P value generates irreproducible results. Nature methods, 12(3), 179-185.

Harrison, L. E. (2000). Culture matters. The National Interest, pp. 55-65. Retrieved from https://nationalinterest.org/article/culture-matters-680?page $=0 \% 2 \mathrm{C} 3$

Intergovernmental Science-Policy Platform on Biodiversity and Ecosystem Services. (2019). Nature's Dangerous Decline 'Unprecedented' Species Extinction Rates 'Accelerating'. Retrieved from https://www.unenvironment.org/news-and-stories/press-release/naturesdangerous-decline-unprecedented-species-extinction-rates

IUCN. (2020). About Protected Areas. Retrieved from https://www.iucn.org/theme/protectedareas/about

La, V.-P., \& Vuong, Q.-H. (2019). bayesvl: Visually learning the graphical structure of Bayesian networks and performing MCMC with'Stan'. The Comprehensive $R$ Archive Network (CRAN).

Leihy, R. I., Coetzee, B. W. T., Morgan, F., Raymond, B., Shaw, J. D., Terauds, A., . . Chown, S. L. (2020). Antarctica's wilderness fails to capture continent's biodiversity. Nature. doi:https://doi.org/10.1038/s41586-020-2506-3

Lubchenco, J., Palumbi, S. R., Gaines, S. D., \& Andelman, S. (2003). Plugging a hole in the ocean: the emerging science of marine reserves. Ecological Applications, 13(1), S3-S7.

Marchese, C. (2015). Biodiversity hotspots: A shortcut for a more complicated concept. Global Ecology Conservation, 3, 297-309.

McElreath, R. (2020). Statistical rethinking: A Bayesian course with examples in $R$ and Stan: CRC press.

Myers, N., Mittermeier, R. A., Mittermeier, C. G., Da Fonseca, G. A., \& Kent, J. (2000). Biodiversity hotspots for conservation priorities. Nature, 403(6772), 853-858.

Naughton-Treves, L., Holland, M. B., \& Brandon, K. (2005). The role of protected areas in conserving biodiversity and sustaining local livelihoods. Annu. Rev. Environ. Resour., 30, 219-252.

Nguyen, M.-H., Ho, M.-T., La, V.-P., Nguyen, Q.-Y. T., Ho, M.-T., Vuong, T.-T., .. . Vuong, Q.-H. (2020). A Scientometric Study on Depression among University Students in East Asia: Research and System Insufficiencies? Sustainability, 12(4), 1498. 
Okamura, K. (2019). Interdisciplinarity revisited: evidence for research impact and dynamism. Palgrave Communications, 5(1), 1-9.

Pauly, M. V. (2011). The trade-off among quality, quantity, and cost: how to make it - if we must. Health Affairs, 30(4), 574-580.

Phillips, A. (2004). The history of the international system of protected area management categories. Parks, 14(3), 4-14.

Pongsiri, M. J., \& Roman, J. (2007). Examining the links between biodiversity and human health: an interdisciplinary research initiative at the US Environmental Protection Agency. EcoHealth, 4(1), 82-85.

Postel, S. L., \& Thompson Jr, B. H. (2005). Watershed protection: Capturing the benefits of nature's water supply services. Paper presented at the Natural Resources Forum.

Reyes-Gonzalez, L., Gonzalez-Brambila, C. N., \& Veloso, F. (2016). Using co-authorship and citation analysis to identify research groups: a new way to assess performance. Scientometrics, 108(3), 1171-1191.

Sahel, J.-A. (2011). Quality versus quantity: assessing individual research performance. Science translational medicine, $3(84), 84 \mathrm{~cm} 13-84 \mathrm{~cm} 13$.

Secretariat of the Convention on Biological Diversity (2015). Tourism supporting Biodiversity A Manual on applying the CBD Guidelines on Biodiversity and Tourism Development. Retrieved from Montreal:

Shah, H. (2020). Global problems need social science. Nature, 577(7790), 295-295.

Sheehan, E. V., Stevens, T. F., Gall, S. C., Cousens, S. L., \& Attrill, M. J. (2013). Recovery of a temperate reef assemblage in a marine protected area following the exclusion of towed demersal fishing. PLOS ONE, 8(12), e83883.

Sievanen, L., Campbell, L. M., \& Leslie, H. M. (2012). Challenges to interdisciplinary research in ecosystem-based management. Conservation Biology, 26(2), 315-323.

Soares-Filho, B., Moutinho, P., Nepstad, D., Anderson, A., Rodrigues, H., Garcia, R., ... Hissa, L. (2010). Role of Brazilian Amazon protected areas in climate change mitigation. Proceedings of the National Academy of Sciences, 107(24), 10821-10826.

Straughan, E., \& Dixon, D. (2012). Cultural response to climate change. Nature Climate Change, 2(7), 480-481.

Taylor, M. F., Sattler, P. S., Evans, M., Fuller, R. A., Watson, J. E., \& Possingham, H. P. (2011). What works for threatened species recovery? An empirical evaluation for Australia. Biodiversity and conservation, 20(4), 767-777.

Thur, S. M. (2010). User fees as sustainable financing mechanisms for marine protected areas: An application to the Bonaire National Marine Park. Marine policy, 34(1), 63-69.

Tydecks, L., Jeschke, J. M., Wolf, M., Singer, G., \& Tockner, K. (2018). Spatial and topical imbalances in biodiversity research. PLOS ONE, 13(7), e0199327.

Victor, D. (2015). Climate change: Embed the social sciences in climate policy. Nature, 520(7545), 27-29.

Visseren-Hamakers, I. J., Gupta, A., Herold, M., Peña-Claros, M., \& Vijge, M. J. (2012). Will REDD+ work? The need for interdisciplinary research to address key challenges. Current Opinion in Environmental Sustainability, 4(6), 590-596.

Vuong, Q.-H. (2018). The (ir)rational consideration of the cost of science in transition economies. Nature Human Behaviour, 2(1), 5-5. doi:10.1038/s41562-017-0281-4

Vuong, Q.-H. (2019). Breaking barriers in publishing demands a proactive attitude. Nature Human Behaviour, 3(10), 1034-1034. 
Vuong, Q.-H. (2020). Reform retractions to make them more transparent. Nature, 582, 149. doi:doi: 10.1038/d41586-020-01694-X

Vuong, Q.-H., Bui, Q.-K., La, V.-P., Vuong, T.-T., Nguyen, V.-H. T., Ho, M.-T., . . Ho, M.-T. (2018). Cultural additivity: behavioural insights from the interaction of Confucianism, Buddhism and Taoism in folktales. Palgrave Communications, 4(1), 143. doi:10.1057/s41599-018-0189-2

Vuong, Q.-H., Ho, M.-T., Nguyen, H.-K. T., Vuong, T.-T., Tran, T., Hoang, K.-L., . . La, V.-P. (2020). On how religions could accidentally incite lies and violence: folktales as a cultural transmitter. Palgrave Communications, 6(1), 82. doi:10.1057/s41599-020-0442-3

Vuong, Q.-H., La, V.-P., Nguyen, M.-H., Ho, M.-T., Ho, M.-T., \& Mantello, P. (2020). Improving Bayesian statistics understanding in the age of Big Data with the bayesvl $\mathrm{R}$ package. Software Impacts, 100016.

Vuong, Q.-H., La, V.-P., Nguyen, M.-H., Ho, M.-T., Tran, T., \& Ho, M.-T. (2020). Bayesian analysis for social data: A step-by-step protocol and interpretation. MethodsX, 100924.

Vuong, Q. H. (2020). The semiconducting principle of monetary and environmental values exchange. Hanoi.

Vuong, Q. H., Ho, M. T., \& La, V. P. (2019). 'Stargazing' and p-hacking behaviours in social sciences: some insights from a developing country. European Science Editing, 45(2), 5455.

Vuong, Q. H., \& Napier, N. K. (2015). Acculturation and global mindsponge: an emerging market perspective. International Journal of Intercultural Relations, 49, 354-367.

Walpole, M. J., \& Goodwin, H. J. (2001). Local attitudes towards conservation and tourism around Komodo National Park, Indonesia. Environmental conservation, 160-166.

Watson, J. E., Dudley, N., Segan, D. B., \& Hockings, M. (2014). The performance and potential of protected areas. Nature, 515(7525), 67-73.

World Bank Group. (2012). Biodiversity: Finding the funds to keep Latin America green. 